\title{
Hybrid Matrix Grafts to Favor Tissue Regeneration in Rabbit Femur Bone Lesions
}

\author{
Dante Pascual Goy ${ }^{\mathrm{a}}$, Emmanuel Gorosito ${ }^{\mathrm{a}}$, Hermes S. Costa ${ }^{\mathrm{b}}$, Pablo Mortarino ${ }^{\mathrm{a}}$, Noelia Acosta \\ Pedemonte $^{\mathrm{a}}$, Javier Toledo ${ }^{\mathrm{a}}$, Herman S. Mansur ${ }^{\mathrm{b}}$, Marivalda M. Pereira, ${ }^{\mathrm{b},{ }^{*}}$, Ricardo Battaglino ${ }^{\mathrm{c}}$ and \\ Sara Feldman ${ }^{\mathrm{a}}$
}

\author{
${ }^{a}$ LABOATEM: Fac Cs Médicas, Universidad Nacional de Rosario, Argentina \\ ${ }^{b}$ Dep. Eng. Metalúrgica e de Materiais, Universidade Federal de Minas Gerais, Brasil \\ ${ }^{c}$ Department of Cytokine Biology, The Forsyth Institute, Boston, Massachusetts, USA
}

\begin{abstract}
At present, typical approaches employed to repair fractures and other bone lesions tend to use matrix grafts to promote tissue regeneration. These grafts act as templates, which promote cellular adhesion, growth and proliferation, osteoconduction, and even osteoinduction, which commonly results in de novo osteogenesis. The present work aimed to study the bone-repairing ability of hybrid matrixes (HM) prepared with polyvinyl alcohol (PVA) and bioactive glass in an experimental rabbit model. The $\mathrm{HM}$ were prepared by combining $30 \%$ bioactive glass (nominal composition of $58 \% \mathrm{SiO}_{2}$ $-33 \% \mathrm{CaO}-9 \% \mathrm{P}_{2} \mathrm{O}_{5}$ ) and $70 \%$ PVA. New Zealand rabbits were randomly divided into the control group (C group) and two groups with bone lesions, in which one received a matrix implant HM (Implant group), while the other did not (no Implant group). Clinical monitoring showed no altered parameters from either the Implant or the no Implant groups as compared to the control group, for the variables of diet grades, day and night temperatures and hemograms. In the Implant group, radiologic and tomographic studies showed implanted areas with clean edges in femoral non-articular direction, and radio-dense images that suggest incipient integration. Minimum signs of phlogosis could be observed, whereas no signs of rejection at this imaging level could be identified. Histological analysis showed evidence of osteo-integration, with the formation of a trabecular bone within the implant. Together, these results show that implants of hybrid matrixes of bioactive glass are capable of promoting bone regeneration.
\end{abstract}

Keywords: Bone regeneration, hybrid matrix, bioactive glass, polyvinyl alcohol, femur bone lesion.

\section{INTRODUCTION}

Several areas such as orthopedic and oncologic surgery, sports injuries, stomatology, neurosurgery, and maxillofacial surgery, may require the use of implant techniques. Many different materials can be used as implants for traumas, lesions, or bone resections [1]. For example, in sixteenth century Europe, iron, silver, and gold implants were used to repair bone. By contrast bone grafts have been frequently used since the beginning of the twentieth century [1]. In the past, the implant served only to replace damaged tissues, with no regenerating capability. The first studies on lesions caused by the presence of an implant were published in the 60's, and the concepts of biocompatibility (defined as the tolerance that a tissue has toward a given material) began to emerge [2]. More recently a new idea has been introduced to make grafts of autologous and allogeneic bones, which will induce the formation of new bones within the transplanted area [3].

The use of allograft bone materials arose due to the limited amount of autologous bone used for implants. The use of human bone implants decreases the risks of

*Address correspondence to this author at the Universidade Federal de Minas Gerais Departamento de Eng. Metalúrgica e de Materiais Escola de Engenharia - Bloco 2 - Sala 3640 Av. Antônio Carlos, 6627-Pampulha 31.270-901 - Belo Horizonte - MG Brasil; Tel: (31) 3409-1845;

Fax: (31) 3409-1810; E-mail: mpereira@ demet.ufmg.br antigenic responses [4. 5] but the risk of infection before and after surgery is increased. In addition, the allogeneic graft can potentially promote the transmission of microorganisms, such as $\mathrm{HBV}$ and $\mathrm{HCV}[6,7]$. The preparation of the material to be implanted must respond to the need to eliminate pathogenic agents of the tissue, in turn preserving its properties [5-8].

A new generation of biomaterials, called third generation, is being developed, and would act as scaffoldings in an attempt to promote the regeneration of tissues $[9,10]$. These new materials must present a specific architecture in which the cells can organize themselves to regenerate the tissue to be replaced. The materials must also provide an initial biomechanical profile until cells produce an appropriate extracellular matrix, after which the initial matrix is degraded or metabolized. Finally, the material must result in the generation of a vital tissue that restores the functions of the original tissue or organ $[11,12]$. For a biomaterial to be considered for an implant, it must promote the regeneration of de novo tissue, as well as be biocompatible and bioactive. In addition, it must be able to replace the injured tissue. If the tissue to be regenerated is bone tissue, in addition to osteoconductivity and osteoinductivity, the material must also present mechanical properties to support the load [13], appropriate porosity, degradation capacity, and ductility to be implanted [14]. 
Intelligent biomaterials, which are able to stimulate the necessary biological responses to reestablish the functions that the tissue had lost as a result of trauma, have been developed $[14,15]$. These new materials are expected to function temporarily. They should regenerate the tissue and then be gradually replaced by the newly formed tissue. The existing biomaterials have not always shown the capacity to accelerate the formation of bones [16]. Bioactive ceramics, such as bioactive glass, can be made as porous matrixes with the capacity for osteoconduction and osteoinduction. However, these rarely present an adequate mechanical behavior due to their low level of toughness. To overcome this problem, a commonly used strategy is the combination of the bioactive ceramic phase with a biocompatible and biodegradable polymer. Porous composite and hybrid scaffolds containing bioactive glass and a polymeric phase may be obtained using the sol-gel process. Hybrid scaffolds in the Polyvinyl alcohol/bioactive glass (PVA/BaG) system have been developed and extensively studied as regards their structure and mechanical behavior [17]. These materials posses both osteoconductive ability and good mechanical properties; however, emerging cytotoxicity problems can arise from the synthesis method itself [18].

Therefore, the present work aimed to: 1) test various polyvinyl alcohol/bioactive glass hybrid materials for in vitro cytotoxicity and select the one presenting the lowest levels of cytotoxicity, and 2) to test the material in an in vivo implant procedure, in an experimental model of $\mathrm{New}$ Zealand rabbit femur bone lesions, considering a) whether or not an integration phenomenon has occurred and b) whether or not an inflammatory phenomena of rejection has occurred.

\section{MATERIALS AND METHODS}

\section{Preparation of Polyvinyl Alcohol Solutions}

The polyvinyl alcohol (PVA), with a hydrolysis grade of $80 \%$ and a MW 9,000-10,000 $\mathrm{g} / \mathrm{mol}$, was acquired from Sigma-Aldrich ( $\left.\mathrm{N}^{\mathrm{o}} 36062-7\right)$. Aqueous solutions of PVA were prepared to $28 \%(\mathrm{w} / \mathrm{v})$, dissolving the powder for two hours at $80^{\circ} \mathrm{C}$, with continuous shaking. The $\mathrm{pH}$ solution was adjusted to 2.0 , with $2 \mathrm{M} \mathrm{HCl}$.

\section{Preparation of Initial Solution of Bioactive Glass (BaG)}

The initial solution of $\mathrm{BaG}$ (with nominal composition $58 \%$ w/w $\mathrm{SiO}_{2} ; 33 \% \mathrm{w} / \mathrm{w} \mathrm{CaO}$; and $9 \%$ w/w $\mathrm{P}_{2} \mathrm{O}_{5}$ ) was synthesized from a mixture of tetraethyl orthosilicate (TEOS Sigma Aldrich No13196-3), deionized water, triethylphosphate (TEP - Sigma Aldrich $\mathrm{N}^{\circ} \mathrm{C} 3881$ ), and calcium chloride(Sigma Aldrich $\mathrm{N}^{\circ} 538728$ ), in the presence of $2 \mathrm{M} \mathrm{HC1}$, and with a mole fraction $\mathrm{H}_{2} \mathrm{O}$ /TEOS equal to 12 .

\section{Preparation of Hybrid Foams of PVA-BaG-GA}

The final composition of the hybrid consisted of $70 \%$ w/w polymer and $30 \% \mathrm{w} / \mathrm{w}$ bioactive glass. The hybrids were obtained using a previously described procedure [17]. A surfactant sodium lauryl sulfate, a $10 \%$ solution of Hydrofluoric acid (HF) and a glutaraldehyde solution (GA) were added to the bioactive glass precursor solution described previously. The final GA concentration was $0 \%$, $1 \%$, or $5 \%$ w/w with respect to the PVA mass in the solution. The mixture was shaken vigorously. The HF solution was added to catalyze the process of gelification, whereas the GA was used as a cross linking agent. The foams obtained were poured in plastic containers immediately before gelification, closed and left for 3 days at $40^{\circ} \mathrm{C}$. Later, they were submitted to drying by opening the container and leaving them at that same temperature for 7 days

\section{Stabilization Process}

Stabilization is performed so as to reduce the acidity of hybrids. For this, the samples were immersed in $0.3 \mathrm{M}$ $\mathrm{NH}_{4} \mathrm{OH}$ solution for 10 hours at $25^{\circ} \mathrm{C}$, in a proportion of 100 $\mathrm{ml}$ of solution for each gram of hybrid dry mass. After this, the samples were washed three times with deionized water, and dried at room temperature and sterilized with ethylene oxide.

\section{Structural Characterization of Samples}

The pore morphology and pore size distribution of the hybrids were analyzed by scanning electron microscopy (SEM), using a JSM 6360LV (JEOL/ NORAM) equipment, coupled to Energy-dispersive X-ray Spectroscopy (EDS), used to analyze the surface composition of the samples. Prior to examination, samples were coated with a thin gold film by sputtering

\section{Cytotoxicity Tests of the PVA-BaG Hybrids}

The hybrids were assayed for cytotoxicity in the following manner: the matrixes were pre-incubated in Eagle's minimal media (MEM) for 22 hours at $37^{\circ} \mathrm{C}$. Next, these matrixes were immediately placed in contact with VERO cells in 96-well plates, (50.000 cells/ well), and incubated for 24 hours at $37^{\circ} \mathrm{C}$. After this, fresh medium was added. Cell viability was evaluated by MTT [3(4,5 dimethylthiazol- eyl) 2,5 diphenyl-tetrazoliumbromide assay, based on the reduction of tetrazolium salt into formazan crystals by dehydrogenase, present in living cells mitochondria. MTT assay was conducted according to the manufacturer's instructions (Sigma-Aldrich). Untreated cells were used as a negative control. Cells treated with $0.1 \% \mathrm{v} / \mathrm{v}$ Triton X-100 were used as positive controls.

\section{Bioactivity in Simulated Body Fluid}

The samples were prepared in a disk shape of $25 \mathrm{~mm}$ radius and $1 \mathrm{~mm}$ thickness, and were immersed in a Simulated Body Fluid (SBF), prepared according to Kokubo [19]. After 7 days, the samples were analyzed with scanning electron microscopy (SEM), using a JSM 6360LV (JEOL/NORAM) equipment, coupled to Energy-dispersive $\mathrm{X}$-ray Spectroscopy (EDS).

\section{Experimental Model}

Three-month old female New Zealand rabbits, kept in individual cages with food and water ad libitum, were randomly divided into a control group and a group with bone lesions. This group was subdivided into two groups, one of which received a HM matrix implant (Implant group -Imp), while the other did not (no Implant group - noI), $(n=6$ for each resulting group).

\section{Pre-surgical Preparation}

Antibiotic prophylaxis and anesthetic treatment were performed according to previously described procedure [2]. Antibiotic prophylaxis was carried out prior to the surgical 
procedure by applying cefazolin at a dose of $50 \mathrm{mg} / \mathrm{kg} / \mathrm{day}$, administered intramuscularly. The anesthetic treatment was peformed by combining three medicines, which were administered intramuscularly: Ketamine Hydrochloride at 35 $\mathrm{mg} / \mathrm{kg} /$ day, Xylazine Hydrochloride (2.0\%) at $18 \mathrm{mg} / \mathrm{kg}$, and Acepromazine Maleato $(1.0 \%)$ at $1 \mathrm{mg} / \mathrm{kg}$. As a result, an excellent anesthesia and complete relaxation of the animal was achieved. This effect lasted for 45 to 60 minutes, which was in accordance with suggestions received from Dr. Sanzana, from Spain (Doctoral Thesis Dr. Eduardo Sanzana, Department of Surgery, Faculty of Medicine, University of Barcelona, Spain).

\section{Surgical Technique}

The area was shaved with an electric shaver, brushed with a $10 \%$ povidone-iodine solution, and immediately covered with fenestrated drapes. The intervention began with a cutaneous longitudinal incision of $4 \mathrm{~cm}$ in the distal lateral area of the femur. Both the medial and lateral flaps were divided, and a non-muscular aponeurotic plane was opened until reaching the desired bone area through the divulsion of the mentioned tissues. The central point of the perforation was marked with a bradawl, and the first hole was immediately cut, using a with a $3 \mathrm{~mm}$ bit attached to a sterile electric motor. Later on, milling was continued using a $6 \mathrm{~mm}$ bit to obtain the desired bone defect of no more than $3 \mathrm{~mm}$ deep. The bone defect was washed with a sterile physiological solution to eliminate detritus; the hemostasis of the lesion was performed using a sterile swab plus gauze. Then, the area was dried with a sterile gauze, and this location became the area where the matrixes, which had been previously rehydrated in the animal's own blood, would be placed or not. The instruments used in the surgical intervention were previously sterilized in ethylene oxide. After having implanted the prosthesis, the lesion was then sutured. The aponeurotic plane was first sutured using resorbable material type $3 / 0$, then the skin was sutured with 3/0 Nylon, and disinfected with iodopovidone.

\section{Post-surgical Studies}

After surgery, radiological studies were immediately carried out on all rabbits, in an attempt to view the lesion and/or the implant at a radiological level (see Fig. 4). As post-surgical control, night and day temperatures studies, as well as hemograms, were performed according to conventional techniques, the grade of food, and the water intake. Tomographic studies, using a Toshiba multislice 16 detectors scanner, were performed at the end of the experiment (45 days).

\section{Exakt Micro -Grinding Method for Resin-Embedded Mineralized Tissue}

The sacrifice of the animals was done as previously done in others experimental models, according to international protocols, using three doses of anesthesia [20]. Processed and methyl methacrylate (MMA) embedded femur segments from two animals were radiographed via Faxitron for proper documentation and to define the plane for sectioning. CBSET employed a previously published method that was adapted from the "Donath Technique" as described in the Exakt Cutting/Grinding Training Manual for the histopathological analysis of tissue embedded in plastic resin

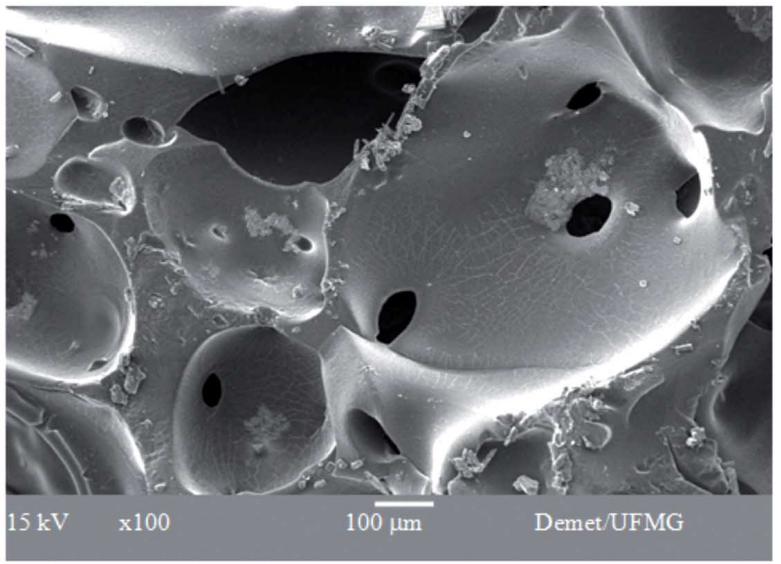

A

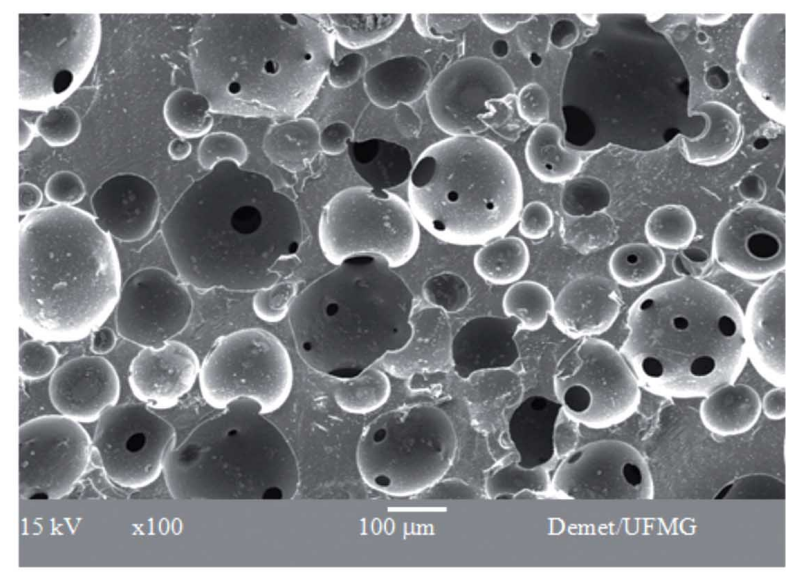

B

Fig. (1). SEM micrograph of PVA/BaG hybrids not cross linked (A) and cross linked with $5 \mathrm{wt}(\%)$ of glutaraldehyde (B).

[21]. MMA embedded femur segments were carefully sawed, using a Buehler Isomet 1000 precision saw. The sections were then mounted on plastic slides, using Technovit 7210 VLC adhesive resin, cured under UV illumination, and micro-ground in an Exakt CS400 grinder, using various sand papers and polished to a final thickness 90 microns. Polished sections were subsequently stained using Toluidine blue [22] and Masson's Trichrome staining procedures [23].

\section{RESULTS}

The structural characterization of the matrixes carried out by electronic microscopy can be seen in Fig. (1). The hybrid matrixes are characterized by a macroporous network for different amounts of GA added. Hybrids that are not cross linked, or cross linked with $1 \% \mathrm{GA}$, present a similar pore structure, in which larger pores (macropores) are interconnected by smaller channels (interconnections). The size range of both macropores and interconnections decrease significantly when the material is cross linked with a higher amount of GA (5 wt $\%$ ). The macropore average diameter was $450 \mu \mathrm{m}$ for the non-cross linked PVA/BaG sample, and $490 \mu \mathrm{m}$ for the cross linked sample with $1 \% \mathrm{GA}$. The average pore diameter reduced to $150 \mu \mathrm{m}$ for samples cross linked with 5\% GA. These results show a pronounced effect of the reticulation on the pore size distribution. 
Cell Viability / contact - Cells VERO x MTT

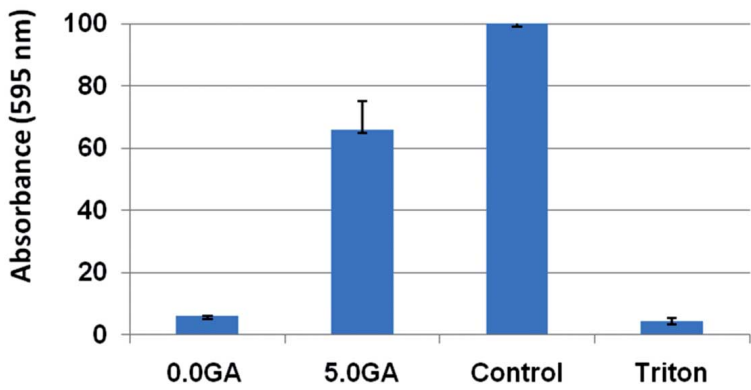

Fig. (2). Cell viability of VERO cells cultured in direct contact with PVA/BaG hybrids not cross linked and cross linked with $5 \mathrm{wt}(\%)$ of glutaraldehyde.
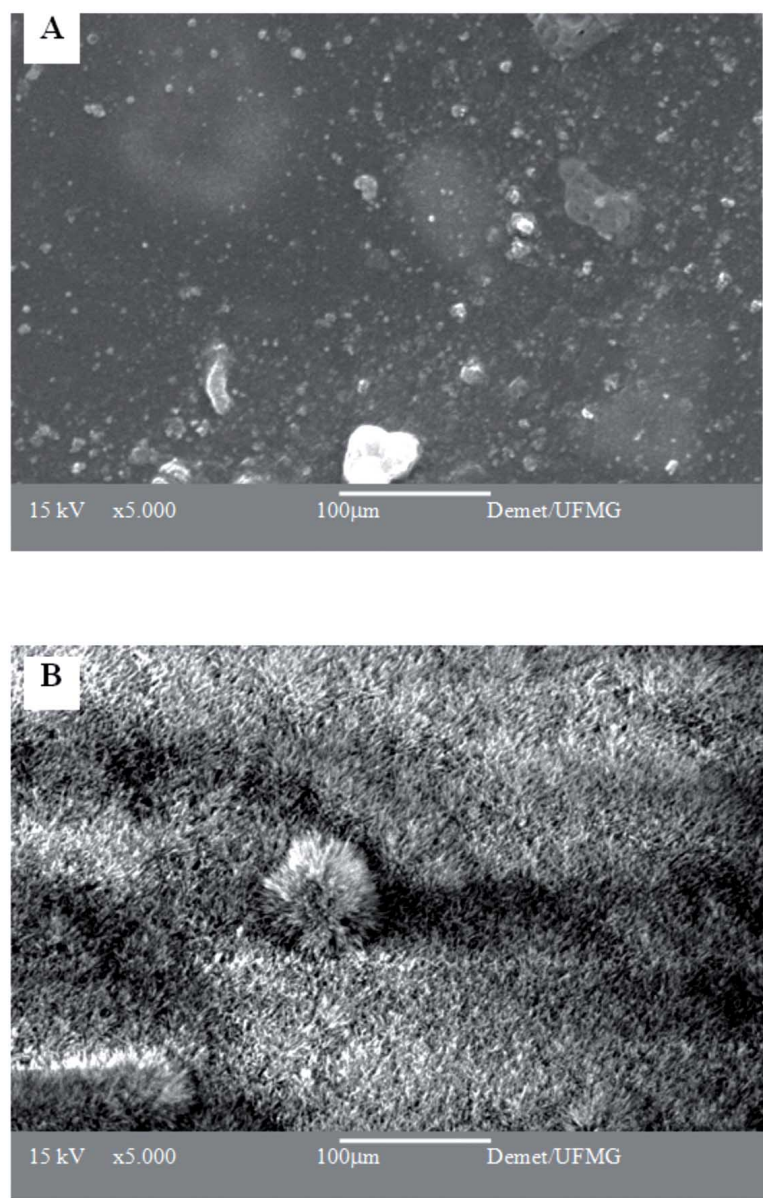

Fig. (3). SEM micrographs of $\mathrm{PVA} / \mathrm{BaG}$ hybrids crosslinked with 5\%GA and stabilized in $\mathrm{NH}_{4} \mathrm{OH}$, after immersion in $\mathbf{A}$ ) water and B) SBF for 7 days.

The cytotoxicity results for matrixes that have been cross linked with different amounts of GA are presented in Fig. (2). The cell viability, when compared to the control cell culture (without the presence of the studied matrixes), decreased for all samples. The cell viability was increased by means of stabilization treatment in an $\mathrm{NH}_{4} \mathrm{OH}$ solution. The sample which presented the higher cell viability, and thus the lowest cytotoxic effect, was the material that had been crosslinked with 5\% GA.

Although the hybrid crosslinked with $5 \mathrm{wt} \%$ GA showed a decrease in the average pore size, this material did present an adequate pore size range (10 to $450 \mu \mathrm{m})$; a better

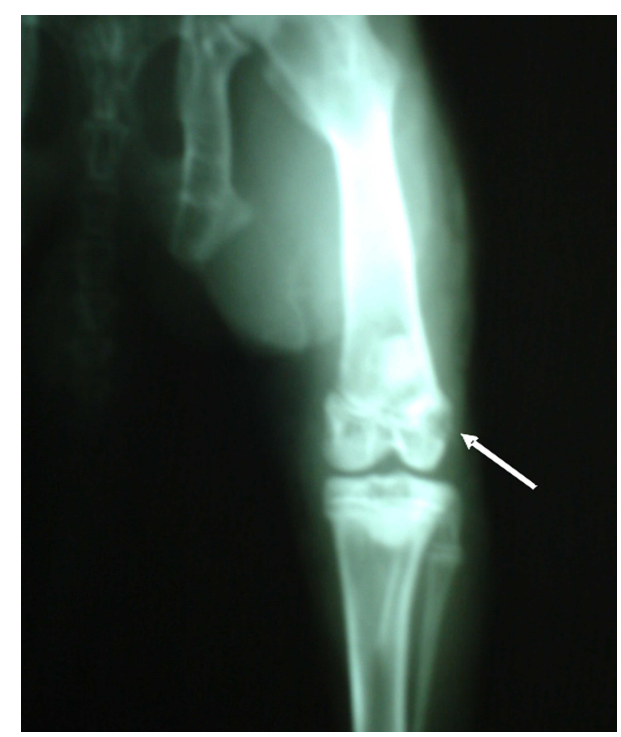

Goy et al.

Fig. (4). Radiological studies clearly showing the implanted area.

mechanical behavior, with a higher yield strength and deformation; as well as a lower degradation rate [24]. The cell viability after stabilization, measured by the MTT test, was $50 \%$, which may also be considered adequate for tissue engineering applications. Therefore, the hybrid crosslinked with $5 \mathrm{wt} \% \mathrm{GA}$, and stabilized by treatment in $\mathrm{NH}_{4} \mathrm{OH}$, was chosen for further in vitro and in vivo studies.

The surface changes of the hybrid matrix upon immersion in an SBF solution for 7 days were evaluated by SEM analysis (Fig. 3). To draw a comparison, samples immersed in water were also analyzed. These samples presented a regular surface with an integral aspect, indicating the resistance of the samples to rapid degradation when in an aqueous medium for 7 days. On the other hand, the surface of the samples immersed in SBF presented a pronounced morphological aspect, indicating the presence of particles in the shape of needles covering the entire visible region. This aspect is compatible with the calcium phosphate deposited in the treated materials, as have been observed for many bioactive materials.

From these results, it could be concluded that the stabilization procedure used can efficiently remove the cytotoxic species and that the treatment with SFB was capable of preparing the materials for contact with the cell medium or in vivo studies.

Once the type of matrix has been selected, the specific lesions and the sample sizes used to test the lesion repair in an in vivo study were defined. The model selected for this study was a femoral bone lesion of three-year old female New Zealand rabbits to consider if the positioning of the mentioned implant did in fact promote the regeneration of de novo bone tissue, and whether or not the rejection phenomena could be discarded. For this, samples of $6 \mathrm{~mm}$ in diameter and $3 \mathrm{~mm}$ in thickness were cut, sterilized with ethylene oxide, and rehydrated in the blood from each animal, prior to their implants under sterile conditions. According to the proposed technique, a simple and practical lesion was obtained with clear edges. Post-surgical radiological studies, performed in the rabbits that received the implant, clearly showed the opaque area of the implant (Fig. 4). 


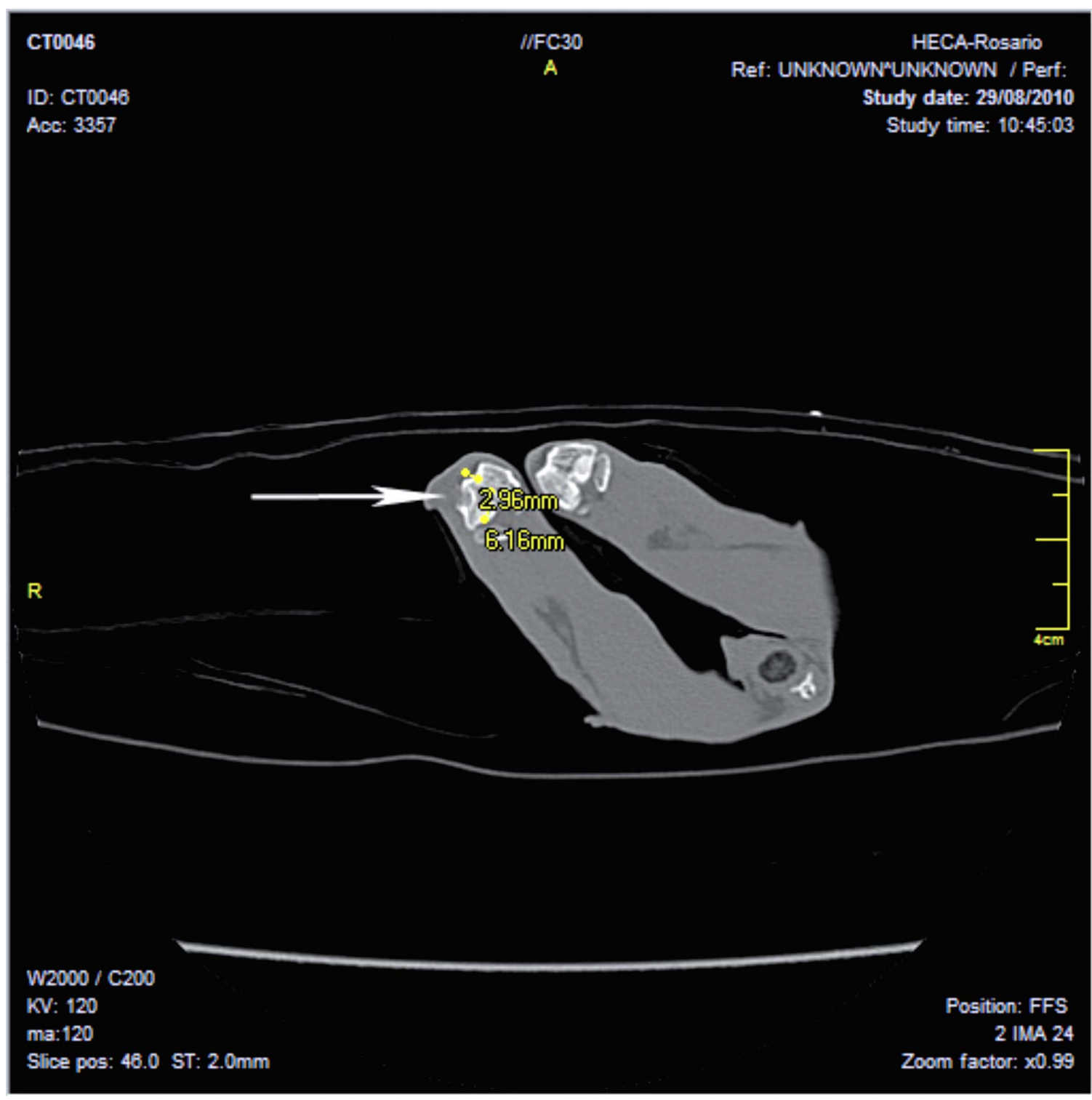

Fig. (5). Image obtained in Multislice CT scanner Toshiba (16 slice) shows a bone lesion in a rabbit femur according to material and method. A radiolucent image with cortical erosion in distal femoral epiphysis of right condyle is observed. Dense image interpreted as signs of incipient integration-regeneration. No swelling of soft tissue is seen.

The developed surgical strategy showed a high level of effectiveness with regard to the parameters of post-surgical monitoring that should be considered when implementing this type of therapeutic strategy, given that the injured rabbits, both those that received the replacement matrixes and those that did not, showed no alterations in water consumption, in day and night temperatures, or in altered patterns in the hemograms ( $\mathrm{p}<0.01$, ANOVA).

After 45 days, tomographic studies (Toshiba multislice scanner) showed, in all animals from the Imp group, punched out implanted areas of clean rim in the non-articular femoral direction, dense images compatible with incipient integration, minimum signs of phlogosis, and no signs of rejection at the imaging level (Fig. 5). By contrast, the noI group presented typical unclean rim lesions in all cases (due to an incipient fibrosis process which is typical in lesions that cannot be resolved through therapeutic strategies, in turn generating fibrous tissue that do not have the characteristics of the original tissue prior to the incision).
Histological analysis showed osteo-integration (Fig. 6), as evidenced by the presence of active cuboidal osteoblasts (white arrow heads), newly deposited osteoids (black arrow heads) and osteocytes (red arrow heads). The trabecular bone formation could also be observed within the implant, and no signs of rejection or inflammatory reaction could be identified.

\section{CONSLUSIONS AND DISCUSSION}

In the present work, a type of hybrid foam (PVA-BaGGA) was obtained using the sol-gel method, and was later cut in a specific volume and shape, to be used as an implant in a femoral lesion model. The synthetized matrix that presented adequate three-dimensional structure and lower degradation rate was selected. As such, the matrix that was synthesized with $5 \%$ of glutaraldehyde as crosslinking agent, generating a structure with average pore diameter of $150 \mu \mathrm{m}$, was selected for this study. The present work shows that the treatment with deionized water or immersion in $\mathrm{NH}_{4} \mathrm{OH}$ 


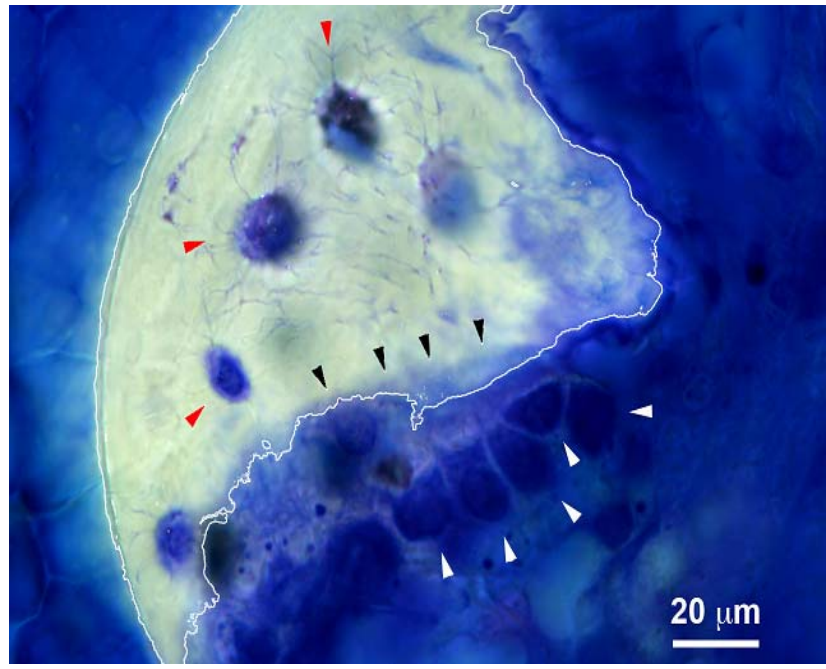

Fig. (6). Toluidine Blue-stained histological section of the distal femur. Several active cuboidal osteoblasts can be observed (white arrowheads) as well as newly deposited osteoid (black arrow heads) and embedded osteocytes (red arrow heads). A piece of calcified trabecular bone (white line) can be observed.

reduces the cytotoxic waste from synthesis process, as can be observed from the results of cell culture when in the presence of the hybrid matrix.

Once the type of matrix to be implanted had been selected, a bone lesion model was then designed, from which surgical strategies of the implant could be implemented. A simple and effective system was developed, in turn avoiding undesirable contamination processes, by rehydrating the matrix in situ with the animal's own blood during surgery. Considering that, in a lesion, bone regeneration has the intention of restituting the tissue ad integrum, thus generating a tissue with biomechanical and functional characteristics similar to the original bone area, the biotechnological developments aimed at optimizing these implant models in depth. Other authors have recently presented encouraging results when considering other types of similar sol-gel type structures, based on bioactive glass intertwined with type II collagen [17-18]. The present work provides evidence that the implants studied showed no rejection, and presented incipient integration, thus indicating that the studied matrixes represent a promising system concerning problems involving bone repair. The present proposal emphasizes the fact that this type of development should be carried out considering the different types of bone repair needs. Offering solutions to problems associated with orthopedic surgery, stomatology, neurosurgery, maxillofacial surgery, and others, requires an in-depth development of these techniques, constantly geared toward resolution of each specific need. The matrixes to be used as implants should be synthesized according to each type and shape of lesion, in an attempt to avoid inappropriate movement of the matrix within the lesion, which could prevent future angiogenesis processes that are essential in generating future de novo bone structure.

\section{CONFLICT OF INTEREST}

None declared.

\section{ACKNOWLEDGEMENTS}

The authors acknowledge the agencies CNPq (Brazil) and CONICET (Argentina) for funding of the present research.

\section{REFERENCES}

[1] W.S. Chase, C.H. Herndon, "The fate of autogenous and homogeneous bone grafts: a historical review", J. Bone Joint Surg., vol. 37A, pp. 809, 1955.

[2] N.A. Peppas, R. Langer, "New Challenges in biomaterials", Science, vol. 263, pp. 1715-1720, 1994.

[3] S. Stevenson, S. E. Emery, V. M. Goldberg, "Factors affecting bone graft incorporation", Clin. Orthop., vol. 324, pp. 66-74, 1996.

[4] D.L. Muscolo, A. Ayerza, E. Calabrese, A. Redal A, and E. Santini Araujo, "Human leucocytee antigen matching, radiographic score and histologic findings in massive frozen bone allografts", Clin. Orthop., vol. 326, pp. 115-126, 1996.

[5] A. Kremenetzky, L. Kremenetzky, and S. Feldman, "Aplicación de Aloinjerto óseo como cemento biológico", Rev. Asoc. Argent. Ortop. Y Traumatol., vol. 71, pp. 61-66, 2006.

[6] E.J. Ortiz Cruz, J.C Loarte, M. Martínez, S.R. Canosa, "Estructura y organización de un banco de huesos y tejidos", Rev. Ortop. Traumatol., vol. 44, pp. 127-138, 2000.

[7] W.W. Tomford, "Transmission of disease through transplantation of musculoskeletal allografts: Current concepts review”, J. Bone Joint Surg., vol. 77A, pp. 1742-1754, 1995.

[8] B. Conway, and W. Tomford, "Radio sensitivity of human immunodeficiency virus type 1", Clin. Infect. Dis., vol. 14, pp. 978979, 1992.

[9] M.M. Pereira, J.R. Jones, R.L. Orefice RL, and L.L. Hench, "Preparation of bioactive glass-polyvinyl alcohol hybrid foams by the sol-gel method", J. Mater Sci.: Mater. Med., vol. 16, pp. 1045$1050,2005$.

[10] A.J. Aho, T. Tirri, J. Kukkonen, N. Stadnberg, K. Rich, J. Seppala, and A. Yli-Urpo, "Injectable bioactive glass/biodegradable polymer compósite for bone and cartilage reconstruction", J. Mater. Sci.: Mater. Med., vol. 15, pp. 1165-1173, 2004.

[11] A.R. Oliveira, V.S. Gomide, M.F. Leite, H.S. Mansur, and M.M. Pereira, "Effect of polyvinyl alcohol content and alter synthesis neutralization on structure, mechanical properties and cytotoxicity of sol-gel derived hybrid foams", Mater. Res., vol. 12(2), pp. 239244, 2009.

[12] Vinatier, D. Mrugala, C. Jorgensen, J. Guicheux, D. Noel, "Cartilage Engineering: a crucial combination of cells, biomaterials and biofactors", Trends Biotechnol., vol. 27(5), pp. 307-14, 2009.

[13] G. Cointry, R. Capozza, S. Feldman, P. Reina, I. Grappiolo, S.E. Ferretti, P. Mortarino, M. Chiappe, J.L. Ferretti, "Los huesos son estructuras genéticas, metabólicas, biomecánicas, o todo a la vez?", Actualizaciones en Osteología, vol. 5(3), pp. 185-195, 2009.

[14] M.S. Muñoz, A.P. M. Rodriguez, F.C. Fernández, K.D. Hernandez, J. Blanco, M. P. Cruz, A. C. Muñoz, J. A. P Moro, "Estudio de la regeneración ósea mediante la implantación endomedular de biomateriales", Patología del aparato locomotor, vol. 3(1), pp. 2430,2005 .

[15] W. Humacher, "Scaffold design and fabrication technologies for engineering tissues--state of the art and future perspectives", $J$ Biomater. Sci. Polymer Ed., vol. 12(1), pp. 107-124, 2001.

[16] B.D. Ratner, A.S. Hoffman, F.J. Schoen, and J.E. Lemons, Biomaterials Science, An introduction to materials in Medicine. Academic Press, New York 1996.

[17] P. Valerio, M.H. R. Guimaraes, M.M. Pereira, M.F. Leite, A.M. Goes, "Primary osteoblast cel responete to sol-gel derived bioactive glass foams", J. Mater Sci.: Mater Med., vol. 16, pp. 851-856, 2005.

[18] H.S. Costa, E.F.B. Stancioli, M.M. Pereira, R.L. Orefice, and H. M. Mansur, "Synthesis, neutralization and blocking procedures of organic/inorganic hybrid scaffolds for bone tissue engineering application", J. Mater. Sci: Mater. Med., vol. 20, pp. 529-535, 2009.

[19] T. Kokubo, H. Kushitani, S. Sakka, T. Kitsugi, and T. Yamamuro, "Solutions able to reproduce in vivo surface-structure changes in bioactive glass-ceramic A-W”. J. Biomed. Mater. Res., vol. 24 (6), pp. 721-734, 1990.

[20] S. Feldman et al., "Effects of hypophysectomy and growth hormone replacement on cortical bone structure and biomechanics in rats", Bone, vol. 34, pp. 203-215, 2004. 
[21] K. Donath, and G. Breuner, "A method for the study of undecalcified bones and teeth with attached soft tissues", J. Oral Pathol. Med., vol. 11(4), pp. 318-326, 1982.

[22] H. Mercer and W.A. Burns, Thick Sections: technique and Applications, Diagnostic Electron Microscopy, John Wiley \& Sons: USA, 1963.
[23] Carson, Histotechnology: A self Instructional text. IL ASCP Press: Chicago, IL, 1997.

[24] H.S. Costa, A.A.P. Mansur, M.M. Pereira, and H.S. Mansur, "Engineered hybrid scaffolds of poly(vinylalcohol)/bioactive glass for bone engineering applications: synthesis, characterization, cytocompatibility and degradation", J. Nanomat., vol. 2012, pp. 1-16, 2012.

Received: March 08, 2012

Revised: May 15, 2012

Accepted: May 29, 2012

(C) Goy et al.; Licensee Bentham Open.

This is an open access article licensed under the terms of the Creative Commons Attribution Non-Commercial License (http://creativecommons.org/licenses/by$\mathrm{nc} / 3.0 /$ ) which permits unrestricted, non-commercial use, distribution and reproduction in any medium, provided the work is properly cited. 